\title{
Opportunities for remanufactured electronic products from developing countries: Hypotheses to characterise the perspectives of a global remanufacturing industry
}

\author{
Alan C. Brent, and Rolf Steinhilper
}

\begin{abstract}
Global legislative and market pressures are increasingly enforcing the concept of product life cycle management (LCM), or product stewardship, particularly in the electronics sector. Thereby, from an environmental perspective, end-of-life regulations and obligations require the technology managers of Original Equipment Manufacturers (OEMs) in developed countries to consider remanufacturing and reuse as an attractive economic alternative to expensive recycling and the final disposal of electronic products. Furthermore, developing countries offer an expanding market for affordable quality spare parts, especially for the repair of cellular phones and household appliances. These dissimilar markets could be complementary from the perspective of the remanufacturing sector. Additional requirements of this relatively informal sector in developing countries must be considered, specifically product cleaning processes and test routines that may necessitate the transfer of technologies. Also, training and formalisation are needed to deliver quality services in the repair sector of developing countries. Potential market niches may also exist for inexpensive products from a formalised remanufacturing industry. Therefore, by moving from international isolation to global integration, remanufacturing and repair will profit from networking and synergy efforts in four arenas of the electronic product life cycle chain: market participants, products and applications, neighbouring technologies, and international regions.
\end{abstract}

Index Terms-life cycle management, product stewardship, remanufacturing, repair.

\section{INTRODUCTION}

$\mathrm{P}$ RODUCTION or manufacturing covers all phases of the life of technical products: manufacturing, including the supply chain and pre-manufacturing, operational use, primarily maintenance and servicing, and also recycling and final disposal [1]. Five critical factors have been identified that currently drive the manufacturing industry [2]:

Manuscript received February 26, 2004.

This work was supported by the Automotive Industry Development Centre (AIDC), through the research activities of its funded Chair of Life Cycle Engineering at the University of Pretoria, South Africa.

A. C. Brent holds the Chair of Life Cycle Engineering in the Department of Engineering and Technology Management, Faculty of Engineering, the Built Environment, and Information Technology, University of Pretoria, Pretoria, 0002, South Africa (phone: 27-12-4203929; fax: 27-12-362-5307; e-mail: abrent@eng.up.ac.za).

R. Steinhilper holds the Chair of Manufacturing and Remanufacturing Technology, Faculty of Engineering Science, Bayreuth University, Bayreuth, Germany (e-mail: rolf.steinhilper@uni-bayreuth.de).
1. A rising consumption of natural resources,

2. A dramatic increase in world population,

3. Environmental impacts, i.e. limited natural resources (energy, minerals, and quality of the ambient air, water and land environment),

4. Global communication networks that are based on standards, and

5. An unstoppable worldwide globalisation.

To reduce these global problems with contributions from production or manufacturing engineering, new orientations and paradigms are required in the manufacturing sector. These requirements have resulted in the demand for product life cycle management (LCM) or product stewardship [3] (see Fig. $1[2]$ ).

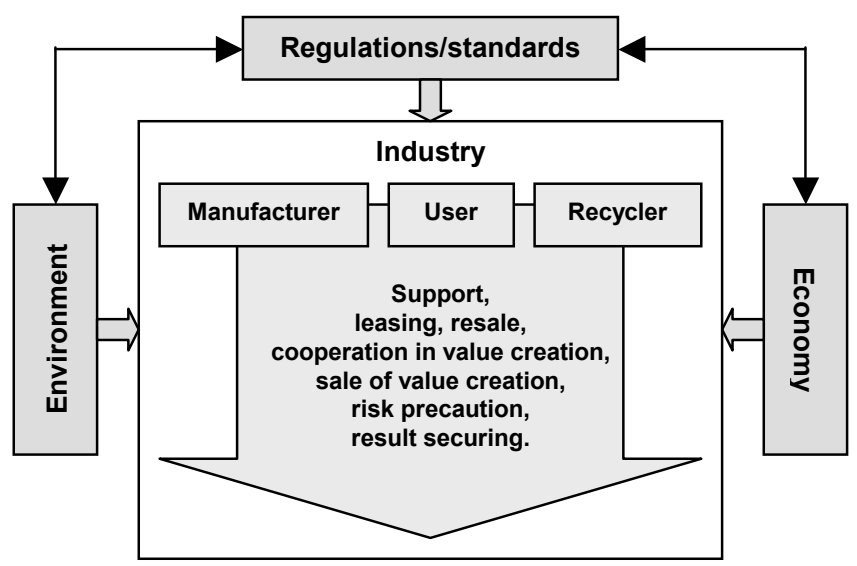

Life Cycle Management

Fig. 1. Demand for Life Cycle Management [2].

Product stewardship, or extended product responsibility (EPR), implies the establishment of partnerships between manufacturers, suppliers, waste handlers, and customers to collectively improve the environmental performances of products [4].

In the high-tech products sector, e.g. electronics, the overall concept of product responsibility is especially important across manufacturing, product use and retirement and recycling [5]. Fig. 2 [5] illustrates the responsibilities that are faced by the electronics-manufacturing sector. Fig. 2 further highlights the future role of recycling (including remanufacturing and reprocessing) of electronic products in order to address the increasing environmental 
responsibilities that are faced by this sector.

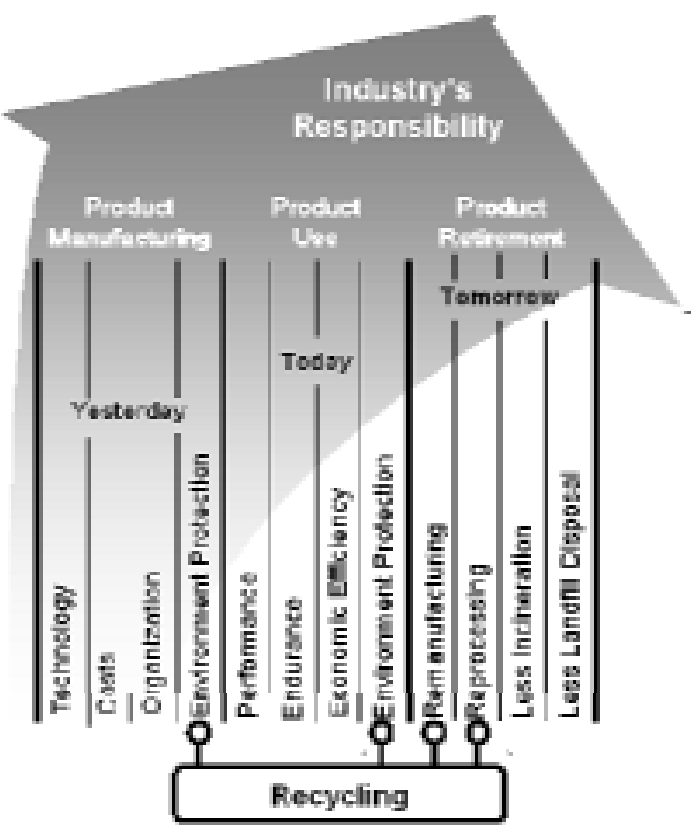

Fig. 2. Industry's responsibility throughout the product life cycle [5].

In order to understand the future role of remanufacturing, and the international opportunities it entails, the characteristics of this sub-sector must be understood. In this respect 10 hypotheses have been introduced to characterise the perspectives of remanufacturing [6].

\section{10 HYPOTHESES TO CHARACTERISE THE PERSPECTIVES OF ELECTRONICS REMANUFACTURING}

\section{A. Markets and legislation both drive remanufacturing}

With current legislative initiatives such as the European WEEE (Waste of Electric and Electronic Equipment) regulations [7] and the IPP (Integrated Product Policy) [8], and related international equivalents, the (re) actions of the electronics industry is often seen as a political push, rather than a market pull. However, the demands of customers will always be the strongest driving forces in the markets in the long term. Furthermore, the strategies, methods and tools of industry, which are typically associated with environmental requirements, are often applied for, or even originate from, economic purposes.

The integrative approach of the "product stewardship" concept, as an example, has originally been introduced as an alliance of all developing parties involved in the design phase of the product life cycle with the aim of a shortest possible "time to market" of the designed products. Furthermore, the coupled partnerships between product and spare parts manufacturers, and maintenance and support parties envisioned a minimum "total cost of ownership" and a perfect "customer relations management" amongst other primary objectives. Thus, the management of the entire product life cycle from its beginning to its end (including the "rebirth" of remanufactured products) is a logical extension of a successful and, to a certain extent, already wellestablished approach.

From an environmental perspective, product stewardship already meets classic challenges in the electronics industry such as product take back regulations and recycling responsibility, and will include future challenges in the area of life-cycle-assessment obligations, recyclability and climate protection declarations, which will have to be presented for each new product intended for specific respective markets.

In addition, recent remanufacturing and reuse initiatives of key role players in the fast moving electronic industry indicate that both economic and environmental approaches exist in order to close the gap between shorter innovation cycles and longer product lives. Thereby, the remanufacturing activities are pushed forward to intensify the public presence in this field and obtain a competitive advantage for market penetration.

A clear trend currently shows that not only reactions to legislation and market developments, but also actions towards the customer are driving remanufacturing through the integrated product policy (IPP) of the European Commission [8]. Although backed up by public policies, these driving forces indicate that the intensified remanufacturing policies of companies are designed to characterise the international markets, and not just to acquire a market segment. This follows on successful business strategies in other industry sectors, e.g. automobile manufacturing [6].

\section{B. Remanufacturing reaches global dimensions}

It is common knowledge that new concepts today spread globally at higher speeds and with higher immediate levels of awareness in all-important markets compared to a decade ago.

In this respect remanufacturing shows continuous two digit growth rates since its inception towards the end of the nineties, which has marked an era of even shorter product innovation cycles and wider product varieties in the electronics product market. These aspects had once been regarded as limiting or killing influences for the concept of remanufacturing, which by its nature extends product lives and requires some quantities of similar products. On the contrary, remanufacturing has experienced a turnaround (see section II.E) and is now expanding to new applications internationally (see sections II.C to II.G).

Remanufacturing, which has long been viewed as the "hidden green giant" by only a few academics, is now attracting the attention of many scientists, executives, newsmakers and politicians [5]. Remanufacturing is, indeed, reaching into more markets than ever before, thereby touching upon all aspects of society [6].

\section{Future automotive remanufacturing is mainly challenged by the remanufacturing of mechatronics and electronics components in automobiles}

Remanufacturing is strongest represented in the automotive sector. At present, automotive products account for two-thirds of all remanufacturing [5].

Modern vehicles contain advanced electronic technologies that monitor or control virtually every function of the vehicle including: brakes, steering, air bags, fuel delivery, ignition, lubrication, theft prevention, emission controls and soon, tyre pressure. It is necessary to have full access to the 
information, parts and tools that are necessary to accurately diagnose, repair, or re-program these systems.

Furthermore, remanufacturing companies increasingly face the challenge of understanding and managing complex mechatronic systems such as electronically controlled automatic transmissions, electrically (not hydraulically) assisted power steering, electrically (not belt) driven water pumps, Integrated Starter and Alternator Devices (so called ISADs), etc. This will require a multidisciplinary approach, which requires access to information and specification data from automotive Original Equipment Manufacturers (OEMs).

To allow this, as well as to assure a free competition in the automotive end-of-life markets of the future, legislative initiatives are underway in both Europe and the USA to ensure free access to the OEMs information data bases and training programmes for independent repair and remanufacturing companies. Thus, an "electronic sealing" of the products by the OEMs is to be avoided. Also, time advantages, more experience and background know-how of the OEMs regarding electronic information within supplied units and components might to a certain extent strengthen the position of OEMs in future remanufacturing markets.

\section{Remanufacturing increasingly manages safety and reliability issues}

Apart from the contributions of remanufacturing in the automotive sector, many other technologies and products are appropriate for remanufacturing, including, but not limited to: industrial robots, copying machines, vending machines, ATMs, computers and cellular phones. The latter is the most recent addition to the remanufacturing field on a global scope and scale and research is underway in this respect (see section II.G).

With state-of-the-art technologies and quality assurance measures being applied, including 100\% inspection, the quality and reliability of remanufactured products is often higher than of similar new products inspected only by random sampling [5]. However, safety and reliability issues still play a key role in serious and often controversial discussions about the future of remanufacturing and reuse of parts.

Besides scientifically proven facts and experiences about failure rates, wear and stress theories and life expectations forecasts, there are also new and wide spread practical examples that remanufacturing has overcome these problems. The widespread use of remanufactured components in the aviation industry is a case in point, where safety of the aircraft is of utmost importance [6].

Reliable technology and supporting theory is therefore available to a wide range of applications that comply with quality management systems and standards such as ISO 9000, which will be accompanied by the ISO 14000 series where applicable. Finally, with the current movements of extending warranty periods, remanufactured electronic parts may in future enter the marketplace with the same warranty as new parts [6].

\section{E. Remanufacturing becomes the essential strategy for affordable spare parts}

Section II.B highlighted the fact that manufacturers are launching new models at shorter intervals. Subsequently it is almost impossible, and certainly economically unfeasible, for manufacturers to supply new spare parts after a product range has been in service for a period.

In order to overcome this problem, manufacturers have four possible strategic options to offer spare parts in the marketplace after the production period of a product:

- Manufacturing and storing the expected overall needed quantity of spare parts at the end of product production on the original manufacturing lines, which can then be dismantled.

- Manufacturing of needed quantities in adequate batches of spare parts on the original production lines, which are kept operational for these purposes, from time to time.

- Manufacturing of needed quantities in adequate spare parts on other flexible production equipment, if available, from time to time.

- Remanufacturing of spare parts from old parts that are obtained from products retiring from the marketplace.

The latter option benefits the electronics-remanufacturing sector as it more and more offers the only affordable and appropriate strategy. If not, the costs for the spare parts availability in the product life cycle would be exploding and unmanageable. The consequence has been the experienced expansion, and conquering of new product areas and markets, of the remanufacturing sectors (see sections II.A to II.B) [5].

\section{F. Reuse and repair concepts celebrate a rebirth}

Direct reuse and repair of parts, together with remanufacturing, are also enjoying support of both economically and environmentally conscious market players in the transportation, electric and electronic industries and the respective products. Especially in the automotive market, insurance companies have entered this market segment in order to cut costs for collision damage waiver packages by supporting accident repairs with used parts. Experts estimate possible annual savings of multi billions of Euros or Dollars for consumers in the worldwide automotive market alone [5]. On the other hand, the negative "backyard" image of reused parts is reflected in the limited warranties that are often given on used parts. Appropriate actions are therefore required to improve the practices in, and image of, the reused parts sector.

The negative image of the reused parts sector especially applies to the so-called developed countries, or the industrialised parts of the world, where unaffordable labour has hampered the expansion of a formalised repairing sector. Consequently, the costs and perceived risks associated with more frequent repair and reuse cannot be justified against normal production operations with established technologies and parts at reasonable prices.

In contrast, affordable labour is readily available in developing countries, while capacities, competences, technical information and skills for repair for a formalised 
repairing sector, are seen as the major hurdles. In these countries the market need for repaired and reused electronic parts originates from the exposure of the societies to, and subsequent unexpected, high-volume demand for, products that are relatively costly when purchased new via international suppliers.

The Information and Communication Technology (ICT) sector in South Africa, with products such as television sets, personal computers and cellular phones, is a good example where repairing and reuse forms a significant market segment of these products $[9,10]$. The relatively high prices of, for example, new mobile units [11] have resulted in a high demand for repaired units in South Africa and other African countries, especially in rural and peripheral-urban communities. The combination of high demand and geographical location has opened the door for small and micro enterprises (SMEs) to fulfil this need, which requires the transfer of necessary skills [12]. However, the lack of detailed information about SMEs has limited the actions that have been taken to develop this informal sector further. It is therefore imperative to obtain a good understanding of the characteristics of these SMEs before their capacities can be utilised to contribute further to the South African ICT sector, e.g. through larger remanufacturing initiatives.

\section{G. Remanufacturing allows multiple and migratory use of products}

New environmental protection research programmes, which top scientists, government authorities, together with leading experts from the industry, are supporting for the future, see product cycles rather as intelligent networks than simple closed loops. In these programmes, tools to support the highest form of product and component reuse, the ability to provide documentation of all components and materials in a product, as well as intelligent networks for the multiple and migratory use of products and modules, are a priority. In this respect industrial applications of considerable scale already exist. A very recent example is the exportation of surplus mother boards from a major European computer OEM, via an independent expert broker, for the conversion to a key equipment part in hundreds of private regional digital TV recording, and soon broadcasting, studios all across the USA.

With respect to the case study in the previous thesis (section II.F), cellular phones could have a multiple and migratory use with a first life in Europe and a second life after remanufacturing in South Africa, i.e. a migration from one continent to another, or a multiple and migratory use with a first life as a cellular phone and a second life as a wireless communication unit in a vending machine, which automatically orders new stock from the supplies as the existing stock diminishes, i.e. a migration from one application to another.

\section{H. Product cleaning processes and test routines require new technologies development}

The remanufacturing of products on an industrial scale, assuring a constant quality level in a series production, follows the standardised sequence of five steps [5]:

1. Disassembly of Product,
2. Cleaning,

3. Testing,

4. Reuse, Reconditioning or Replacement of Parts, and

5. Reassembly of Product.

While steps 1,4 , and 5 still profit from valuable knowhow and experiences from the manufacturing of new products, steps 2 and 3 will, in the near future, require considerable research and development efforts towards new cleaning processes and test routines.

Cleaning processes, which are much more than washing away dirt and dust from the parts, but also de-greasing, derusting, de-oiling and freeing parts from old paint, have become more "environmentally friendly" in the past years. The future will also need more "product friendly" and "material friendly" cleaning technologies; on one hand removing any unwanted layers from the parts' surfaces efficiently, on the other hand not interacting with more and more delicate products or difficult materials in new remanufacturing applications.

Test routines also offer new challenges for future remanufacturing products. The development of new objective criteria besides the classic condition characteristics of components (line geometric dimensions and electric/electronic functionality) will become increasingly necessary. This data, rather than an actual appearance of a product, promise to forecast a reliable second life (or application) of a product.

Furthermore, where remanufacturing is considered in developing countries, the transfer of knowledge pertaining to these (and future) complex cleaning processes and test routines would also entail a separate challenge for intelligent global remanufacturing networks.

\section{Remanufacturing profits from networking}

The vision of remanufacturing, i.e. from isolation to integration, drives networking and synergy efforts in the product life cycle chain in four arenas:

1. Market participants,

2. Products and applications,

3. Neighbouring technologies, and

4. International regions.

Following the characteristics of "knots and links", or inter linkages, each network profits from main synergies, enjoys opportunities and strengths, as well as suffers from risks or weaknesses, which all deserve attention (see Table I).

TABLE I

CHARACTERISTICS OF NETWORKS IN PRODUCT LIFE CYCLE CHAINS

\begin{tabular}{ll}
\hline \multicolumn{1}{c}{ Network } & \multicolumn{1}{c}{ Characteristics } \\
\hline Market & $\begin{array}{l}\text { Knots and Links: OEMs, Remanufacturers, Repair } \\
\text { businesses, Market dealers. } \\
\text { Main Synergies: Product cycle market development, } \\
\text { economic and ecologic benefits. } \\
\end{array}$ \\
& $\begin{array}{l}\text { Opportunities and Strengths: High growth potential. } \\
\text { Risks and Weaknesses: Competition vs. Cooperation. }\end{array}$ \\
Products and & $\begin{array}{l}\text { Knots and Links: Electric and electronic consumer } \\
\text { products, Machine tools and Manufacturing Equipment. }\end{array}$ \\
& $\begin{array}{l}\text { Main Synergies: Sharing of new technologies } \\
\text { development. }\end{array}$ \\
& $\begin{array}{l}\text { Opportunities and Strengths: Cooperative support for } \\
\text { product cycles. }\end{array}$ \\
& Risks and Weaknesses: Lack of communication.
\end{tabular}


Neighbouring Knots and Links: Manufacturing, Remanufacturing, technologies Repairing, Reusing, Recycling.

Main Synergies: Best choices for product life extension. Opportunities and Strengths: Higher customer awareness for product cycles.

Risks and Weaknesses: Quality of second hand products, Image of product life cycle technologies.

International Knots and Links: Western Europe, Eastern Europe, North regions America, Japan, Southeast Asia, Central/South America, Africa, etc.

Main Synergies: Successful labour cost management,

Employment, Sufficient product supply; also in individual regions with limited purchasing power.

Opportunities and Strengths: More than one market,

Global efforts for the environment.

Risks and Weaknesses: Transport efforts, Ecologic bottom-line.

\section{J. From product remanufacturing to modernization factories}

While the supply chain side of the manufacturing cycle of a product has seen considerable progress to offer tailor made solutions for customers by successful approaches such as mass customisation technologies, the service and aftermarket-side of the product life cycle still requires innovation towards successful solutions of global integrated remanufacturing approaches, which are customer oriented, economically feasible and ecologically beneficial.

Here tertiary education and applied research can moderate and be of valuable methodological assistance, not only for manufacturing, but also for remanufacturing.

This has commenced in many institutions around the globe, where there is now more communication and cooperation compared to confrontation in the past because of competition.

Therefore, if with further progress a vision beyond remanufacturing is searched for, the concept of "modernization factories", covering both existing and newly evaluated remanufacturing products, might lead to the exploration of new technological and organizational solutions in the electronic industry.

\section{ICT REPAIR CASE STUDIES IN THE COMMERCIAL SECTOR OF SOUTH AFRICA}

Two ICT repair cases were undertaken in South Africa during 2003 in order to investigate the hypotheses pertaining to remanufacturing in the context of developing countries:

- The repair of cellular or mobile units; and

- The repair of home appliances, i.e. radios, Hi-Fi's, VCR's and television sets.

\section{A. The repair of cellular or mobile units}

Cellular phones are increasingly popular in the rural and peripheral communities of South Africa. However, the costs associated with owning these units often fall outside the budgets of individuals within these communities. If individuals do own cellular or mobile phones, the cost of new units and the distances to central large repair facilities, justify the establishment of smaller repair businesses within these communities. A good example of such a typical business is P. Jones Cellulars, which is located in a shopping complex in Temba, a peripheral community that forms part of the greater Pretoria metropolitan area, which is situated approximately 50 kilometres due north of the city centre within rural agricultural activities. The business was started in 1996, and is owned and managed by 24 year-old Phillip (Philly) Jones Mataboge, who is also solely responsible for all the repair work. The total area of the business is approximately $20 \mathrm{~m}^{2}$, with half allocated to the sales of cellular phone accessories and the other half to cellular phone repairs. At least 40 cellular phones are repaired each month and a financial breakdown (of the repair part) of the business shows a minor share of labour cost and a major share of capital and parts cost (see Table II).

TABLE II

FinANCIAL ESTIMATES FOR THE P. JONES CELLULARS SME IN TEMBA

\begin{tabular}{lll}
\hline \hline \multicolumn{1}{c}{ Description } & Expenses & Income \\
\hline $\begin{array}{l}\text { Once-off capital expenditure, including } \\
\text { infrastructure (in the shop) and } \\
\text { equipment, e.g. hot air station for } \\
\text { soldered parts removal. }\end{array}$ & R 10000.00 & \\
\hline $\begin{array}{l}\text { Rental, including electricity, etc. per } \\
\text { month }\end{array}$ & R 250.00 & \\
$\begin{array}{l}\text { Wages, for two assistants, per month } \\
\text { Running costs (average), for repair } \\
\text { components, etc. }\end{array}$ & R 2 000.00 & \\
\hline Income (total average) & R 1 000.00 & R 5 000.00 \\
\hline Profit (average) & & R 1 750.00 \\
\hline \hline
\end{tabular}

P. Jones Cellulars employs two assistants that are responsible for the sales of the accessories and to purchase repair parts from central Pretoria (by minibus taxi). Philly, the owner of P. Jones Cellulars, has had no formal training in cellular phone repairs, but his father did repair other household electronic equipment such as television sets, etc., and the basic skills were therefore passed along within the family. Repairs are often carried out while customers are waiting.

As cellular phone models change from time to time, and to be able to cope with these changes, P. Jones Cellulars is required to purchase cellular manual books. These comprehensive manuals range in price, but are approximately equal to the cost of three or four repairs, and are therefore extremely affordable. The manuals, depending on the number of models included, provide detailed schematic diagrams of the different models, together with a description of the components that may be the cause of common problems (experienced by users). Both manuals and components are purchased from a store in Pretoria, which has a section allocated to cellular phones. The manuals and components are typically imported from China.

1) The repair of other ICT products

Circumstances and available manuals, similar to cellular of mobile phones, also characterise the situation in the home appliance repair business such as TV sets, HIFI stereos and videocassette recorders. For the purposes of this paper, this case study is therefore not discussed in detail.

\section{B. Conclusions from the cases studies}

The repair of electronic equipment in Africa is an extremely viable business, albeit minor repairs that can be managed by relatively low skilled individuals. This can be 
ascribed to the following:

- The set-up costs of new businesses, especially in peripheral-urban areas, are reasonably low.

- The running costs associated with businesses are also low, compared to other parts of the world, especially rental and labour-rates.

- The required or expected profit margins are extremely low. This is due to the comparative shortage of employment opportunities.

- Warranties are not usually given (in rural and peripheral-urban areas) and the risks are relatively low, although customer satisfaction (and "word by mouth") is extremely important in some instances.

The case studies further indicate that there is clear evidence that technical information and skills in the repair sector can be sourced successfully, and with notable quality, from countries and continents other than those of the OEMs. The possibility therefore exists to formalise the repair sectors in developing countries, and integrate and align these sectors to address the international market needs.

\section{CONCLUSIONS}

End-of-life regulations and obligations increasingly require the technology managers of OEMs in developed countries to consider remanufacturing and reuse as an attractive economic alternative to expensive recycling and the final disposal of electronic products. From the perspective of an international manufacturing industry developing countries, especially, provide inexpensive remanufacturing options in an integrated global remanufacturing market. Furthermore, developing countries offer an expanding market for affordable quality spare parts, especially for the repair of cellular phones and household appliances. Thereby, an offset point can be created for electronics products, which implies the multiple and migratory use of products in the global marketplace. Also, additional requirements of the informal sector in developing countries should be considered, specifically product cleaning processes and test routines that may necessitate the transfer of technologies. Also, training and formalisation is required to deliver quality services in the repair sector. In addition, potential market niches may exist for inexpensive products from a formalised remanufacturing industry in developing countries.

\section{ACKNOWLEDGMENT}

The authors would like to thank the SME businesses in South Africa that participated in the ICT repair case studies.

\section{REFERENCES}

[1] T. E. Graedel, Streamlined Life-Cycle Assessment. New Jersey: Prentice Hall, 1998.

[2] E. Westkämper, L. Alting, and G. Arndt, "Life cycle management and assessment: approaches and visions towards sustainable manufacturing," Keynote Paper, CIRP General Assembly, Sydney, Australia, in 2000 Proc Instn Mech Engrs, vol. 205, part B, pp. 599626.

[3] United States Environmental Protection Agency (US EPA), "Product Stewardship," http://www.epa.gov/epaoswer/non-hw/reduce/epr/, accessed on 23 February 2004.
[4] United States Environmental Protection Agency (US EPA), Extended Product Responsibility: A Strategic Framework for Sustainable Products. EPA530-K-98-004, Washington, 1998.

[5] R. Steinhilper, Remanufacturing: The Ulitmate Form of Recycling. Stuttgart: Fraunhofer IRB Verlag, 1998.

[6] R. Steinhilper, and A. C. Brent, "Saving Product Lives in Global and Local Remanufacturing Networks: A Scientific and Commercial Work Report and an Outlook," in Proceedings of EcoDesign 2003: Third International Symposium on Environmentally Conscious Design and Inverse Manufacturing, Tokyo, Japan, EcoDesign2003/1E-8, pp. 297-302.

[7] United Kingdom Department of Trade and Industry (DTI), "Sustainable Development and Environment: EC Directive on Waste Electrical and Electronic Equipment (WEEE)," http://www.dti.gov.uk/sustainability/weee/, accessed on 24 February 2004.

[8] European Commission (EC), "Integrated Product Policy," http://europa.eu.int/comm/environment/ipp/home.htm, accessed on 24 February 2004.

[9] Statistics South Africa, "Standard Industrial Classification Coding System," Statssa website, http://www.statssa.gov.za/default3.asp, accessed on 1 August 2003.

[10] A. C. Brent, Personal communications with Statistics South Africa, 2003.

[11] T. Kelly, and M. Minges M, "Mobile Cellular: Cutting the cord," Presentation at the CTO Annual Council, Gaborone, Botswana, 1999.

[12] Information Systems, Electronics and Telecommunications Technologies (ISETT), Information Systems (IT), Electronics \& Telecommunications Sector Education \& Training Authority (ISETT SETA): Sector skills plan 2000/2001, Report version 4.4, http://www.isett.org.za, accessed on 1 August 2003. 